\title{
A feasibility and implementation model of small-scale hydropower development for rural electrification in South Africa: A case study of Kwa Madiba SSHP Plant
}

\author{
Gideon Johannes Bonthuys ${ }^{1 *}$, Marco van Dijk' ${ }^{1}$ and Jayant Narsee Bhagwan ${ }^{2}$ \\ 'Department of Civil Engineering, University of Pretoria, Pretoria, 0001, South Africa \\ ${ }^{2}$ Water Research Commission, Private Bag X03, Gezina, 0031, South Africa
}

\begin{abstract}
Large numbers of households and communities will not be connected to the national electricity grid for the foreseeable future due to high cost of transmission and distribution systems to remote communities and the relatively low electricity demand within rural communities. Small-scale hydropower used to play a very important role in the provision of energy to urban and rural areas of South Africa. The national electricity grid, however, expanded and offered cheap, coalgenerated electricity and a large number of hydropower systems were decommissioned. In this study, a feasibility and implementation model was developed to assist in designing and financially evaluating small-scale hydropower (SSHP) plants. The implementation model describes steps to be followed in identifying a technically possible and economically feasible opportunity to develop a SSHP site for rural electrification. The development model was used in designing the Kwa Madiba SSHP plant. The Kwa Madiba SSHP plant was economically evaluated on net present value, internal rate of return, levelised cost of energy, financial payback period and cost/benefit ratio. The outcome of this study proved that it is technically possible to provide SSHP installations for rural electrification in South Africa that are more feasible than local or national electricity grid extensions or even alternative energy sources such as diesel generators. It was concluded that the levelised cost of SSHP projects indicates that the cost of SSHP for low energy generation is high compared to levelised cost of coal-fired power generation. However, the remoteness of SSHP for rural electrification increases the cost of infrastructure to connect remote rural communities to the national electricity grid. This provides a low cost/benefit ratio and renders technically implementable SSHP projects for rural electrification feasible on this basis.
\end{abstract}

Keywords: small-scale hydropower, rural electrification, feasibility, Kwa Madiba.

\section{INTRODUCTION}

The major role that access to energy services plays in economic development is generally recognised. However, the linkages between the provision of energy and poverty alleviation through economic development are not fully understood and it can be argued that this lack of understanding contributes to the relatively slow pace of energisation of the African continent (Szewczuk, 2010). The South African Government is committed to universal access to electricity across South Africa. With $80 \%$ of urban areas and $45 \%$ of rural areas electrified the emphasis of the South African Electrification Programme is shifting from the urban to the rural areas of South Africa (Szewczuk, 2015). Feasible grid electricity is being extended as far as is possible into the rural areas. However, large numbers of households and communities will not be connected to the national electricity grid for the foreseeable future due to high cost of transmission and distribution systems to remote communities, the relatively low electricity demand within rural communities and the current expenditure on upgrading and constructing of new coal-fired power stations.

Small-scale hydropower used to play a very important role in the provision of energy to urban and rural areas of South Africa. In South Africa, the concept of generating electricity using water turbines was first suggested in 1879 for lighting purposes in Cape Town (Barta, 2002) and Pretoria by using small-scale

\footnotetext{
* To whom all correspondence should be addressed. ๔ +27 76412 4035; e-mail: gj.bonthuys@gmail.com Received 7 December 2015; accepted in revised form 6 September 2016
}

hydropower schemes. The national electricity grid, however, expanded and offered cheap, coal-generated electricity and a large number of hydropower systems were decommissioned. The South African Renewable Energy Database (Muller, 1999), developed by the CSIR, investigated the available renewable energy resources in the country, including the potential for hydropower. Hydropower has since evolved and has several diverse applications. Today, small hydropower projects are the most commonlyused option to supply electricity to isolated or rural communities throughout the world, including countries such as Nepal, India, Peru and China.

A high efficiency of energy conversion means that smallscale hydropower plants produce about $60-80 \%$ of the total potential energy into power output. The high efficiency of small-scale hydropower suggests that it would be a suitable and feasible option to generate electricity in rural areas. However, uncertainty as to the feasibility of such plants in comparison to alternative or existing energy resources has played a major role in the choice of the most applicable solution. Also, the legislation and policies in place with respect to renewable energy still seem to consider small-scale hydropower as a less favourable option in South Africa.

Furthermore, water scarcity in South Africa has threatened the viability of hydropower as a renewable source of energy. Even so, only a fraction of the potential available for hydropower has been exploited and the lack of explicit models on the sustainable generation and supply of energy using small-scale hydropower for South Africa reduces the possibility of these potential small-scale hydropower installation being investigated as viable energy alternatives. There is also a general lack of awareness of the prospects that small-scale hydropower offers amongst local 
stakeholders. Small hydropower can play a critical role in providing energy access to remote areas in South Africa as stand-alone isolated mini-grids (Van Dijk et al., 2014).

A feasibility and implementation model was developed to assist in designing and financially evaluating small-scale hydropower (SSHP) plants. The implementation model describes steps to be followed in identifying a technically possible and feasible opportunity to develop a SSHP site for rural electrification. The model was used in designing the Kwa Madiba SSHP plant. Note: prices are quoted in South African Rands (ZAR) and represented by the symbol 'R'.

\section{IMPLEMENTATION MODEL}

A model was designed and constructed for the feasible implementation of a SSHP project for rural electrification in South Africa. The model can also be implemented for international projects by varying cost equations and currencies to project- and country-specific values.

The implementation model describes steps to be followed in identifying a technically possible and feasible opportunity to develop a SSHP site for rural electrification. The different sections within the model, based on the research and SSHP designs done, are outlined and explained in subsequent sections. Figures 1 to 3 show the three different sections, namely, site selection, SSHP, and cost, which combine to form the complete implementation model. Continuous referral to implications outlined in either the preceding or subsequent sections of the implementation model provides a comprehensiveness to the model which allows for a sustainable implementation of the SSHP project, from the conceptual phase to the commissioning of the plant.

\section{Site selection}

From the basic mathematical relationship for the potential power output from hydro-turbines, two important parameters for the selection of the potential sites are head and flow available (Wagner and Mathur, 2011). These are the two most important factors; without these small-scale hydropower generation is not possible.

The use of geographic information systems (GIS) as an assessment tool for hydropower has led to a leap forward in the strengthening of the evaluation of the power potential of water streams in the case of the spatial variability of different factors affecting stream power. However, for a reliable assessment of real SSHP site feasibility, site-specific 'on the ground' surveying is needed. But the traditional assessment can be greatly facilitated using GIS techniques that involve the spatial variability of catchment characteristics (Punys et al., 2011).

Not all sites which have sufficient head or flow available are feasible SSHP sites. In turn not all rural communities are in remote areas that will not be connected to the national electricity grid for the foreseeable future. The site selection process therefore starts from one of two scenarios: either there exists a remote rural community in need of basic electricity or there exists a section of river with available head and flow for small-scale hydropower.

From the basic mathematical relationship that the potential power output is directly proportional to the flow through the turbine and the pressure head available, it is clear that for the same energy output, the higher the available head is, the lower the flow needed for the same power generation. This is beneficial for two main reasons:
- Less flow needs to be diverted from the river through the penstock, which minimises environmental impact on the flow within the river section.

- The lower the flow needed through the turbine, the smaller the physical dimensions of the turbine (i.e. in the case of crossflow turbine) become and the lower the cost of the turbine becomes.

The first reason, for lower flow and higher head, also has an environmental impact motivation. The more water being rerouted from the natural watercourse, the higher the environmental impact on the river system would be. Care should be taken to not only never run the river section dry but also to keep flow at an acceptable depth for the biotic components of the river system.

For this reason sites should be chosen with adequate historical flow data records to calculate the total available flow for SSHP generation. From this total flow available for SSHP and the total available head, the total SSHP potential power generation is calculated. This potential power generation must be compared to the needs of the community. If a technically possible SSHP site does not produce enough power to meet the needs of the community it must then either the site should be utilized to serve a different community, the project be abandoned as a whole, or the needs of the community reviewed. An additional option is to, in addition to the SSHP, provide the community with solar, wind, or diesel power for those periods in the year when not enough flow is available to obtain the required power solely through SSHP.

From the confirmation that the potential power generation meets the community energy requirements, a physical site visit is required to confirm flow and head data (Punys et al., 2011). If data errors are observed, field measured data must be used to follow the site selection process and to confirm power generation potential.

Secondary site selection parameters of technically possible SSHP plants, which financially influence the project, should be considered at this stage in the implementation model so as to eliminate surprise costs and the abandonment of the project at either costing or construction stage. Such parameters include the accessibility of the site, social impact, and required infrastructure as well as legal and regulatory aspects. The 'Feasibility assessment of the water energy resources of the United States for new low power and small hydro classes of hydroelectric plants' (Hall, 2006) feasibility criteria that were used to identify feasible potential project sites address the land use and environmental sensitivities, prior development, site access, load and transmission proximity and future grid extensions.

\section{Small-scale hydropower (SSHP)}

The accessibility of the site as well as the infrastructure required will determine the type of SSHP scheme to be developed, i.e., a run-off-river scheme (Carrasco, 2011), a kinetic hydropower scheme, a low-head hydropower scheme (Loots et al., 2015) or a combination of any of the three, etc. The difference in scheme will have a cost implication for the project.

Once the SSHP scheme has been decided, the available head and flow will determine the ranges and types of hydro-turbines to be used in the design. The type and range of turbines will in turn have implications for the amount of flow to be utilised for certain available heads and vice versa. Different turbines also have different efficiencies and power ratings which has implications for the total potential power generation and therefore the community requirements. Care should be taken to compare data during design to assumptions made during the site selection stage in order to ensure the compliance of the design to the initial goals of the project. 


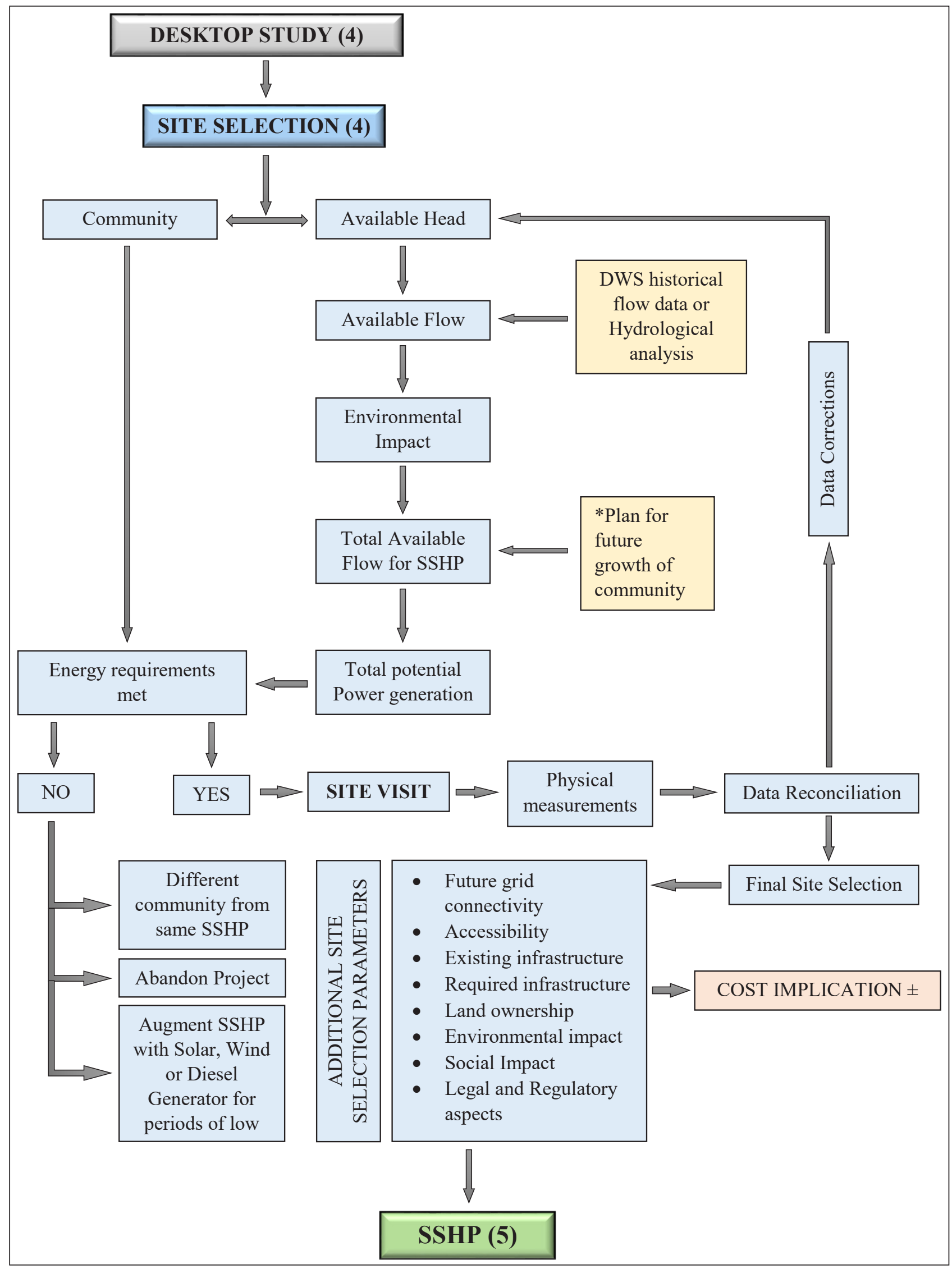

Figure 1

Implementation model: site selection 


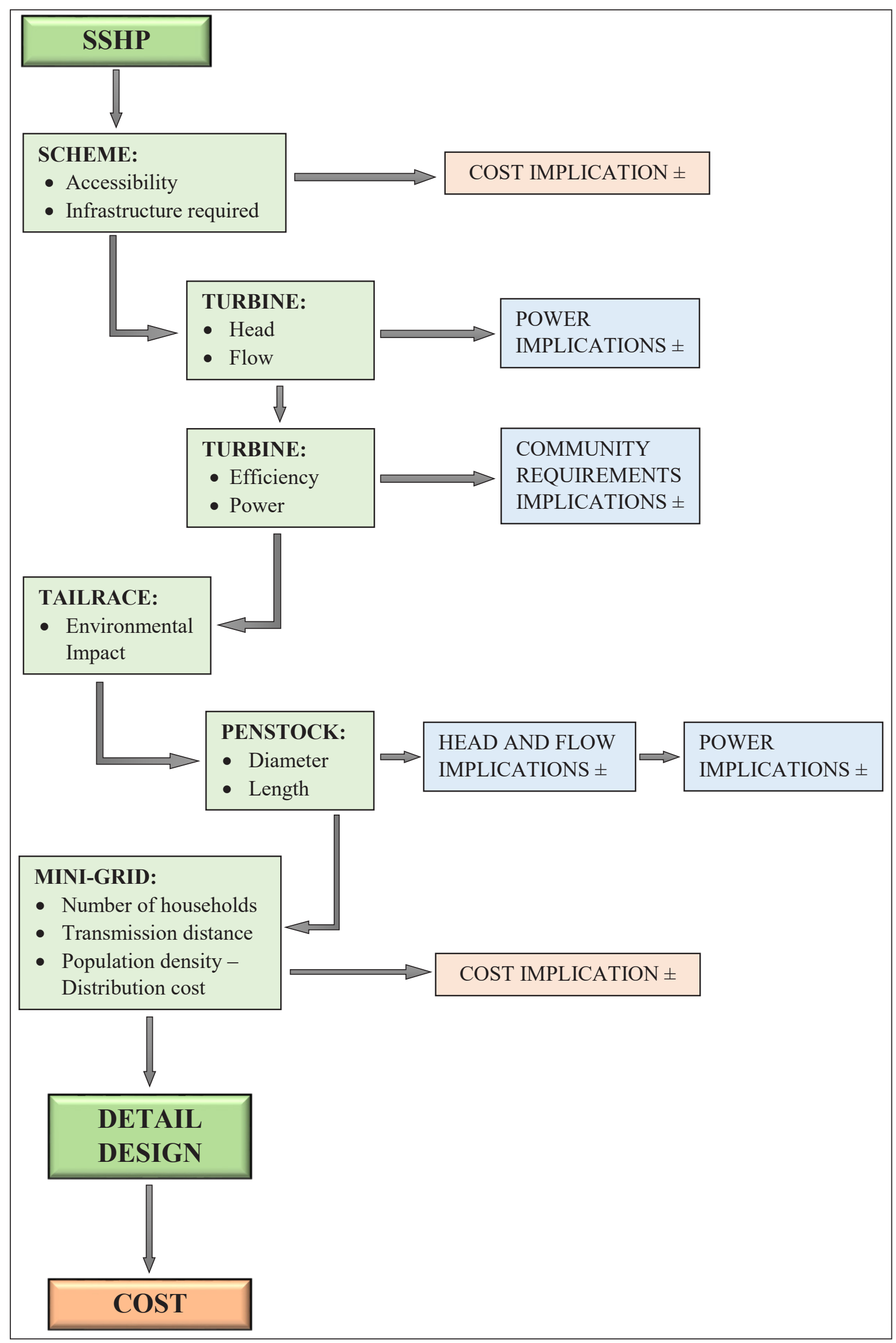

Figure 2

Implementation model: Small-scale hydropower 


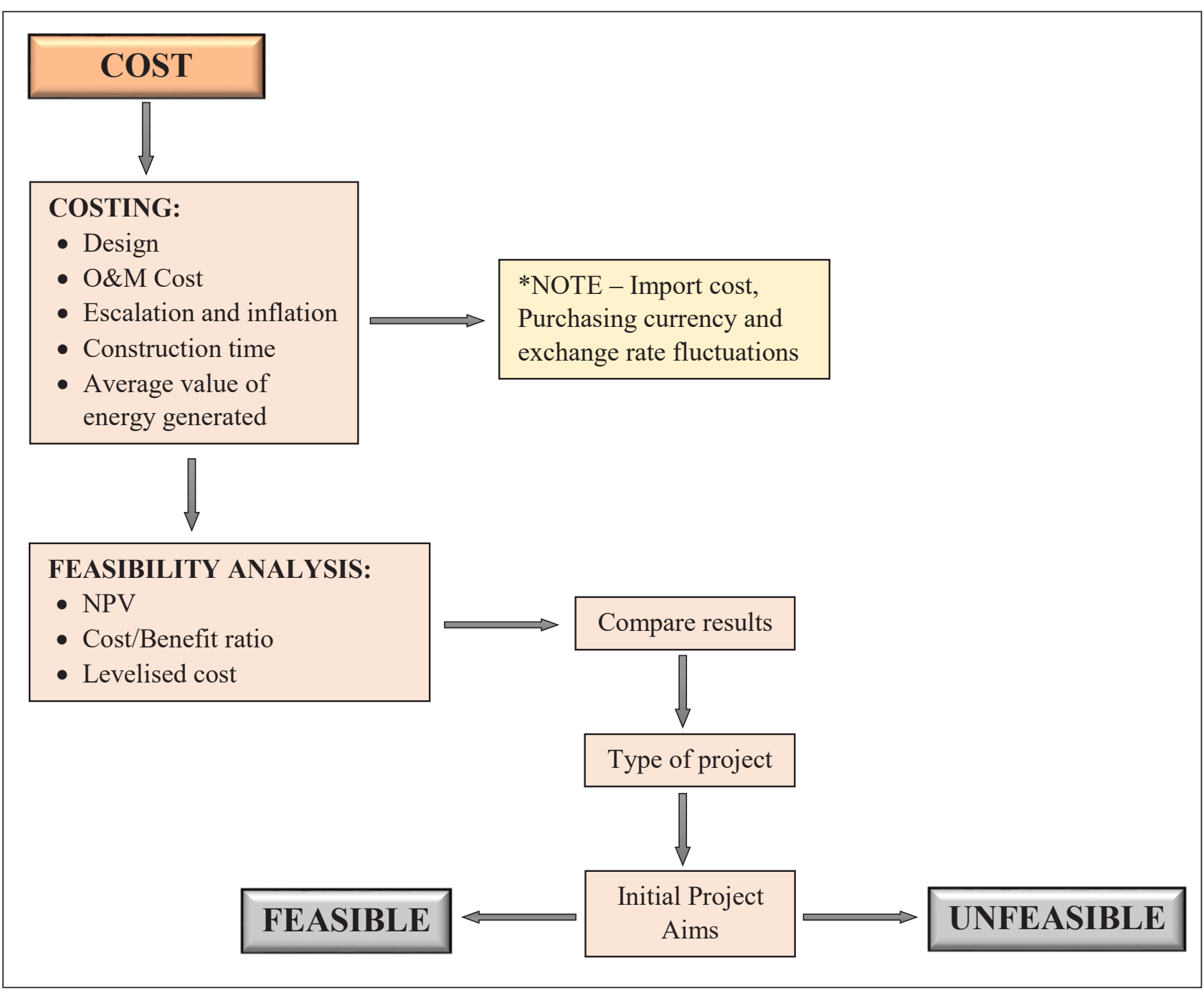

Figure 3

Implementation model: cost

Figure 4 shows the layout of a typical run-off-river hydropower scheme inclusive of an intake, canal and forebay, penstock and powerhouse. The typical run-off-river hydropower scheme also includes a tailrace or discharge structure. The tailrace, or discharge structure, is located downstream of the turbine and takes the water discharged from the turbine back to the watercourse (Colorado Energy Office, 2007). The release from the turbine room into the tailrace and to the downstream river or stream conditions has an environmental impact which must be noted and mitigated as far as possible. If excessive scour should be present from the SSHP design, the design must be amended.

The penstock sizing has implications for both the cost of the project as well as the amount of flow and head loss, which in turn has implications for the potential power generation and community requirements. Care must be taken to design the penstock so as to limit the frictional head loss and flow restriction while also keeping the cost at a feasible level. A sensitivity analysis is recommended in this regard.

Designing the mini-grid layout of the SSHP scheme has implications for the cost of the scheme. Transmission lines which are too long will render a project unfeasible and the sporadic nature of households in communities with a low population density will increase the distribution costs of the project. These factors must be considered before moving to the detailed design and the cost of the potential SSHP scheme.

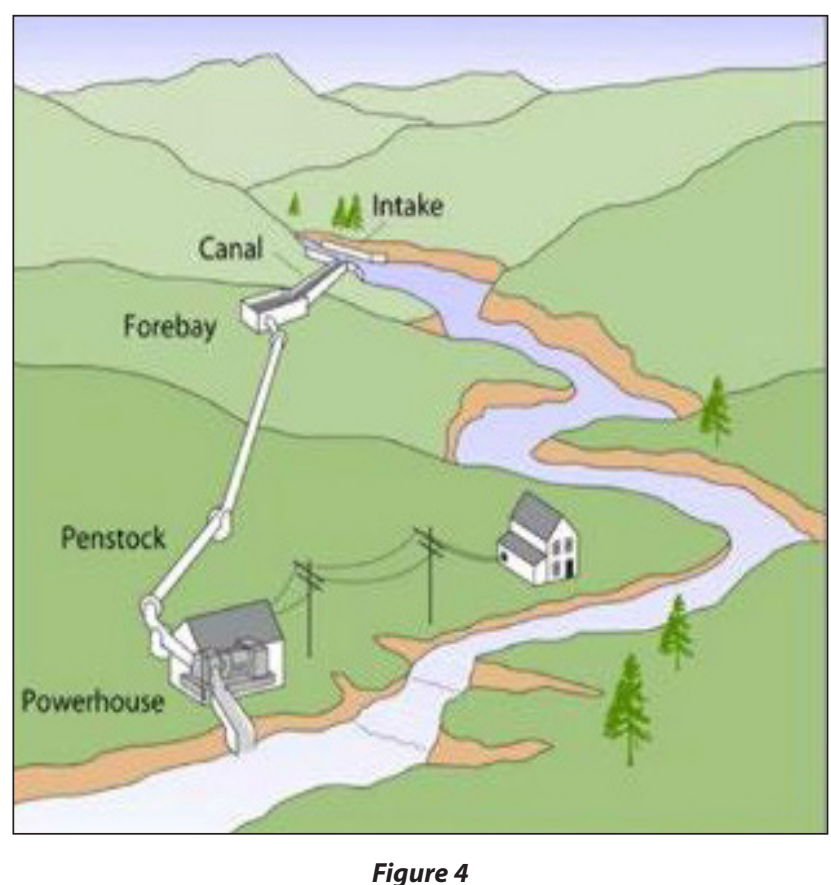

Typical run-off-river scheme (Wade et al., 2015) 
TABLE 1

The costing of the SSHP scheme follows the costing of any basic project. Due to the fact that there are few locally manufactured hydro-turbines the import cost and the purchasing currency as well as exchange rate fluctuation have a great impact on the cost of the project, and depend on the construction time and the time of procurement of the imported materials. With steep increases in electricity costs in South Africa at present the average value of the generated electricity plays a major role in the feasibility of the project.

Zhang (2012) divides hydropower project costing into three stages: development and construction stage, operation and maintenance stage and the end-of-life stage. In the developed implementation model a SSHP project is divided into two costing stages: a design and construction stage and an operation and maintenance stage (see Figs 1 to 3).

Lastly the project cost is evaluated on NPV, cost/benefit ratio and levelised cost. Some technically possible SSHP projects have negative NPVs based on long transmission line lengths or low income from power generated, but these projects are still possible for rural electrification. Levelised cost of SSHP is high for low power generation yet cost/benefit ratios for SSHP with high levelised cost could still indicate feasibility of SSHP for rural electrification.

\section{KWA MADIBA CASE STUDY}

\section{Site selection}

The geometrical layout of the Thina Falls in the Thina River (Fig. 5), within the Mhlontlo Local Municipality, (Province?) as well as the relatively high perennial flows within the Thina River, offer a feasible opportunity for small-scale hydropower development. From the hydrological analysis of the flow data record obtained from the T3H005 (Mahlungulu) gauging station from the Department of Water and Sanitation online database (www.dwa.gov.za/hydrology), it could be concluded that a flow rate of $640 \mathrm{~L} / \mathrm{s}$ is present within the Thina River at Thina Falls $95 \%$ of the time.

The total theoretical hydropower generation at Thina Falls, utilizing all the flow present in the river at $95 \%$ of the time and incorporating the total height difference between the upstream and downstream levels of the Thina Falls, amounts to $350 \mathrm{~kW}$. This potential reaches megawatts when higher flows are utilized within higher flow periods; it is however only available $5 \%$ of the time and does not rationalize the capital expenditure to install larger equipment to accommodate the higher potential.

Innovative design using directional drilling to construct the penstock from an upstream intake to a downstream turbine room/powerhouse allows for the rerouting of small amounts of flow for hydropower generation while still maintaining the bulk of the flow over the Thina Falls and obtaining a $\pm 50 \mathrm{~m}$ head difference.

From satellite imagery and a physical site visit, the Kwa Madiba settlement was found to be the nearest rural settlement to the Thina Falls potential hydropower site. The physical distance from the proposed turbine room/powerhouse to the end users was measured as $1140 \mathrm{~m}$. The site visit also confirmed no existing electrical infrastructure within Kwa Madiba and no planned extensions of the national electricity grid to the area. The 2011 census showed 117 households with a population of 450 within the Kwa Madiba rural settlement (Census, 2011),

\begin{tabular}{|l|c|}
\hline \multicolumn{2}{|c|}{ KABLE 1 } \\
\hline Design flow rate & $150 \mathrm{~L} / \mathrm{s}$ \\
\hline Design head & $48.8 \mathrm{~m}$ \\
\hline Design power output & $50.0 \mathrm{~kW}$ \\
\hline Penstock length & $158 \mathrm{~m}$ \\
\hline Transmission line length & $1140 \mathrm{~m}$ \\
\hline Number of households & 39 \\
\hline
\end{tabular}

although from the site visit the amount of households appeared to be less, at approximately 39 households.

Several other site selection parameters were used to evaluate the Kwa Madiba potential small-scale hydropower site, which include accessibility by vehicle, current electrical grid connection and future electrical grid connectivity, environmental impact and social impact. Okot (2013) evaluates hydropower plants under economic, social and environmental aspects. Economically, hydropower has a low operating and maintenance cost, socially it improves the standard of living, and environmentally it produces no atmospheric pollutant and no waste (Okot, 2013).

Environmentally the Kwa Madiba/Thina Falls potential hydropower site will have minimal to no impact on the environment due to the fact that only small amounts of flow will be rerouted through the directionally drilled penstock for hydropower generation. Small amounts of flow are sufficient due to the high available head difference at the Thina Falls. The social impact on the community is positive, as the 39 households without electricity will be provided with power from the hydroturbine installed downstream of the Thina Falls. The introduction of electricity to the community and the added possibility/ opportunity of connecting a pump to the electrical supply for pumping raw water to the community for the irrigation of their crops as subsistence farmers, further uplifts the social standing of Kwa Madiba. The introduction of electricity to the community also allows for the opportunity of developing the Thina Falls as a tourist attraction enabling a contribution to the economic development of the community.

\section{Small-scale hydropower (SSHP)}

The Kwa Madiba SSHP scheme was designed as a run-offriver scheme on the Thina River within the Mhlontlo Local Municipality in the OR Tambo District Municipality of the Eastern Cape Province. The intake is located at the top of the Thina Falls and the turbine room and tailrace is located at the bottom of the Thina Falls approximately $65 \mathrm{~km}$ downstream of the N2 Thina River Bridge. The intake and the turbine room are connected by a $42 \mathrm{~m}$ x $355 \mathrm{~mm}$ diameter intake pipeline and a $116 \mathrm{~m} \times 355 \mathrm{~mm}$ diameter penstock constructed through directional drilling. Table 1 shows an overview of the technical data of the Kwa Madiba SSHP scheme.

The infrastructure components of the Kwa Madiba SSHP scheme are categorised into three sections, namely, civil components, electro-mechanical components and electrical components. A summary of the infrastructure components of the Kwa Madiba SSHP schemes is as follows: 


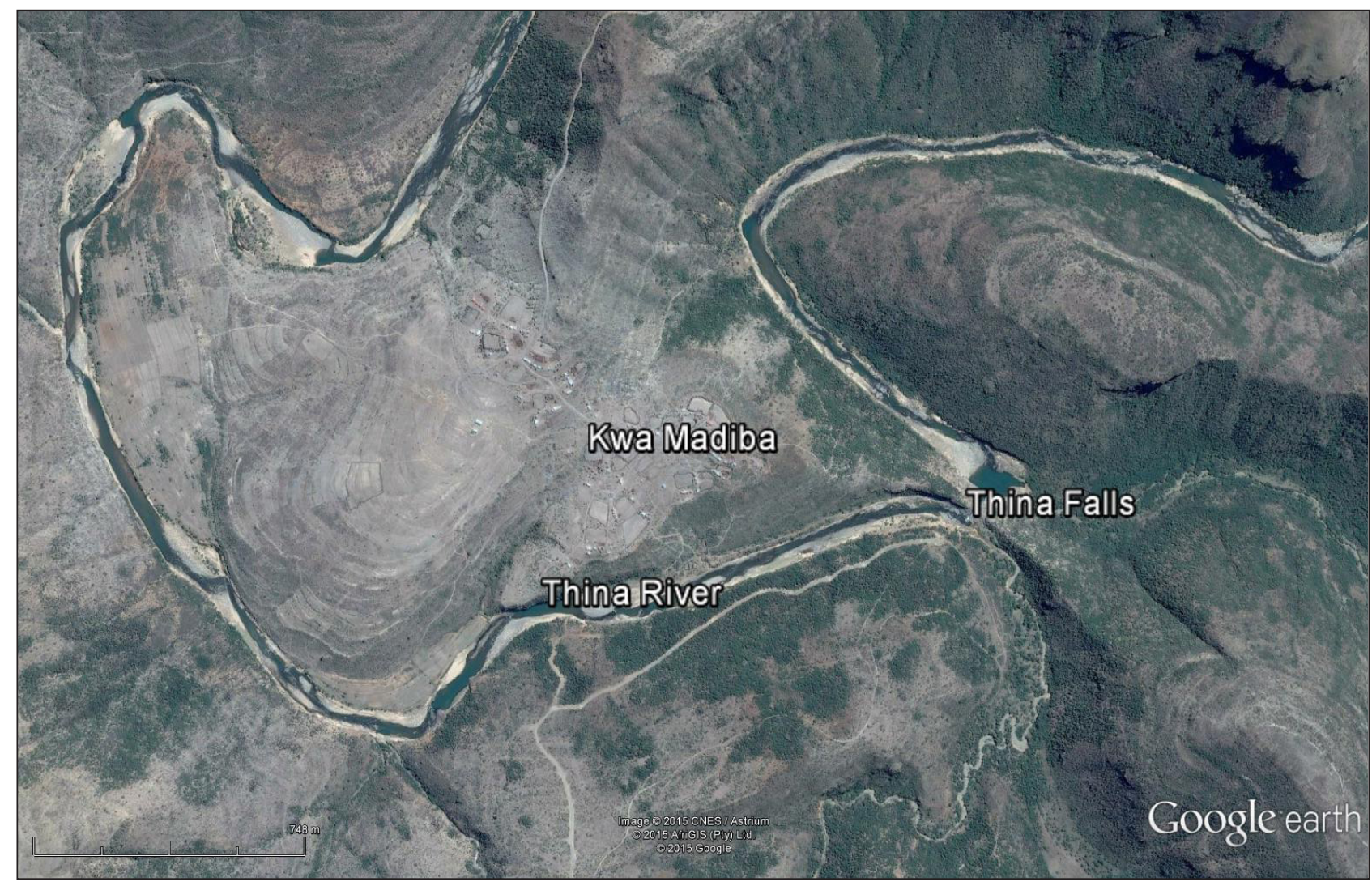

Figure 5

Thina River (Image: Google Earth)

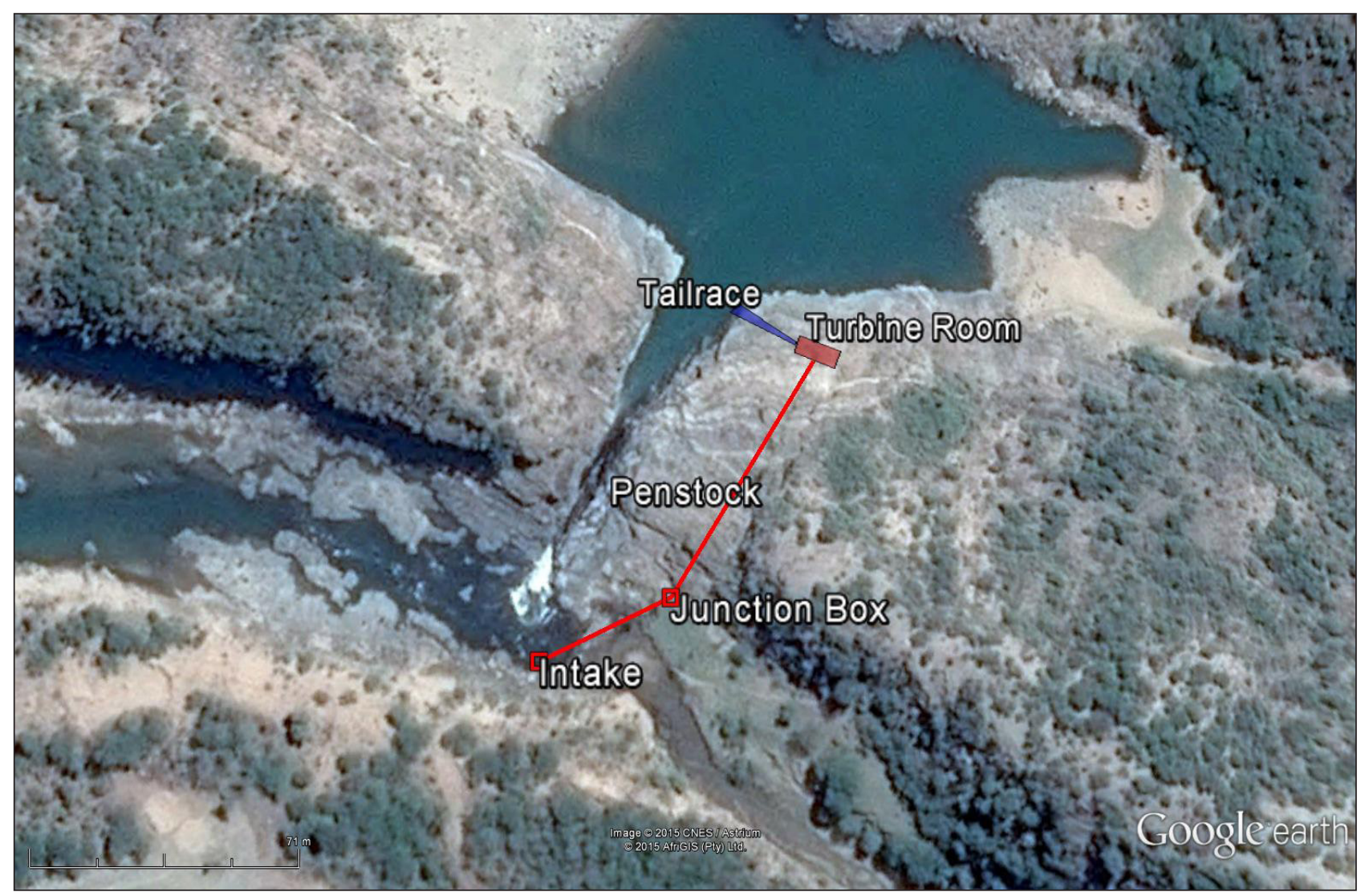

Figure 6

Kwa Madiba SSHP plant: Layout 
- Civil components

- Intake with primary screen and cleaning rack

- $42 \mathrm{~m}$ x $355 \mathrm{~mm}$ Class 6 HDPE intake pipeline

- $116 \mathrm{~m}$ x 355 mm Class 6 HDPE penstock

- $18 \mathrm{ft}$ containerised turbine room

- Tailrace

- Electro-mechanical components

- IREM ECOWATT Micro hydroelectric power plant type TBS 2

- Cross Flow turbine in stainless steel type 4-0.5

- Synchronous generator type AS60

- Electrical components

- Regulators: Electronic Regulating System RMP 10.000/B with water dissipation resistances

- Switchgear/control unit

- Transformers

- Transmission lines

- Distribution lines

- Prepaid electricity units

Figure 6 shows the layout of the Kwa Madiba SSHP plant from intake to turbine room. Figure 7 shows a photograph of the members of the Kwa Madiba community at the downstream side of the Thina Falls taken during a site visit.

The design head and flow produces a potential power generation which meets the requirements of the community. The design was therefore seen as a technically possible and viable design for rural electrification for the Kwa Madiba community. Costing and a financial analysis of the Kwa Madiba SSHP project was done on the design as per the implementation model.

\section{Costing}

The designs for the site were priced and analysed financially. The designs for the site were priced using pricing models obtained from the civil construction industry from both contracting and consulting engineers. The pricing models refer to financial tools used by contracting engineers or civil contractors for tender pricing purposes and financial tools used by consulting engineers for estimating purposes. The pricing models were populated with current material prices received from several local and international pipe and pipe fitting manufacturers and distributors.

A scheduled bill of quantities was developed and compiled for the design. A financial analysis was done for the site to calculate and evaluate the following factors:

- $\quad$ Net present value (NPV)

- Internal rate of return (IRR)

- Levelised cost of energy

- Financial payback period

- Cost/benefit ratio

For the calculation of the NPV for each selected site or potential plant the cost from the scheduled bill of quantities was used as the capital cost under the following items:
- Planning and design costs

- Civil works

- Electro-mechanical equipment

- Implementation costs

It is envisaged that electricity from the SSHP will not be sold to end users on a c/kW basis, but that a certain amount of electricity will be provided to each household for a nominal operation-cost fee which is yet to be finalised. Due to this fact there is no actual annual income from the renewable energy but rather a saving in annual expenditure on electricity procured from the electrical utility by the local municipality.

Annual operation and maintenance (O\&M) costs of the SSHP were calculated as a percentage of the capital cost, as per industry standards, and assumed escalation factors were used to calculate the NPV of each component of the annual O\&M cost. The O\&M cost components were calculated as follows:

- Civil works $\quad=0.25 \%$ of civil works capital costs

- Transmission $=0.8 \%$ of transmission and distribution capital costs

- Operation $=0.4 \%$ of total capital costs excluding plan ning and design costs

- Insurance $=0.3 \%$ of total capital costs excluding plan ning and design costs

- Electrical and mechanical works $=2.0 \%$ of electromechanical equipment (turbines, generators and controls) capital costs

Due to the volatility of interest and inflation rates certain current assumptions were made for the NPV calculations. These assumptions are only accurate at any specific point in time. A sensitivity analysis was done based on, e.g., different inflation rates or different discount rates. The following assumptions, based on current market trends and energy costs, were made and applied to the NPV calculations:

- Escalation of operational costs $=8 \%$

- Escalation of maintenance cost $=10 \%$

- Escalation of other costs

$$
=10 \%
$$

- Escalation of coal fired generation energy costs

- Discount rate (value of capital)

$=10 \%$

- Construction time

$$
=5 \%
$$

- Expected operational life

$=1$ year

- Average value of generated electricity $=40$ years (Eskom Ruraflex tariff structure, 2013)

$=0.59 \mathrm{R} / \mathrm{kWh}$

The cost/benefit ratio of each installation was calculated by comparing the capital cost of the installation to the capital cost of providing electrical infrastructure (transmission and distribution lines) to connect the rural settlement or community to the existing local or national electricity grid. The cost/benefit ratio does not take into account the cost of the electricity sales from the grid or the discounted cost of electricity from the small-scale hydropower plant. The cost/benefit ratio also does not take into account electricity sales from the smallscale hydropower plant but assumes that the electricity from the SSHP is supplied at a nominal cost which only covers annual operation 


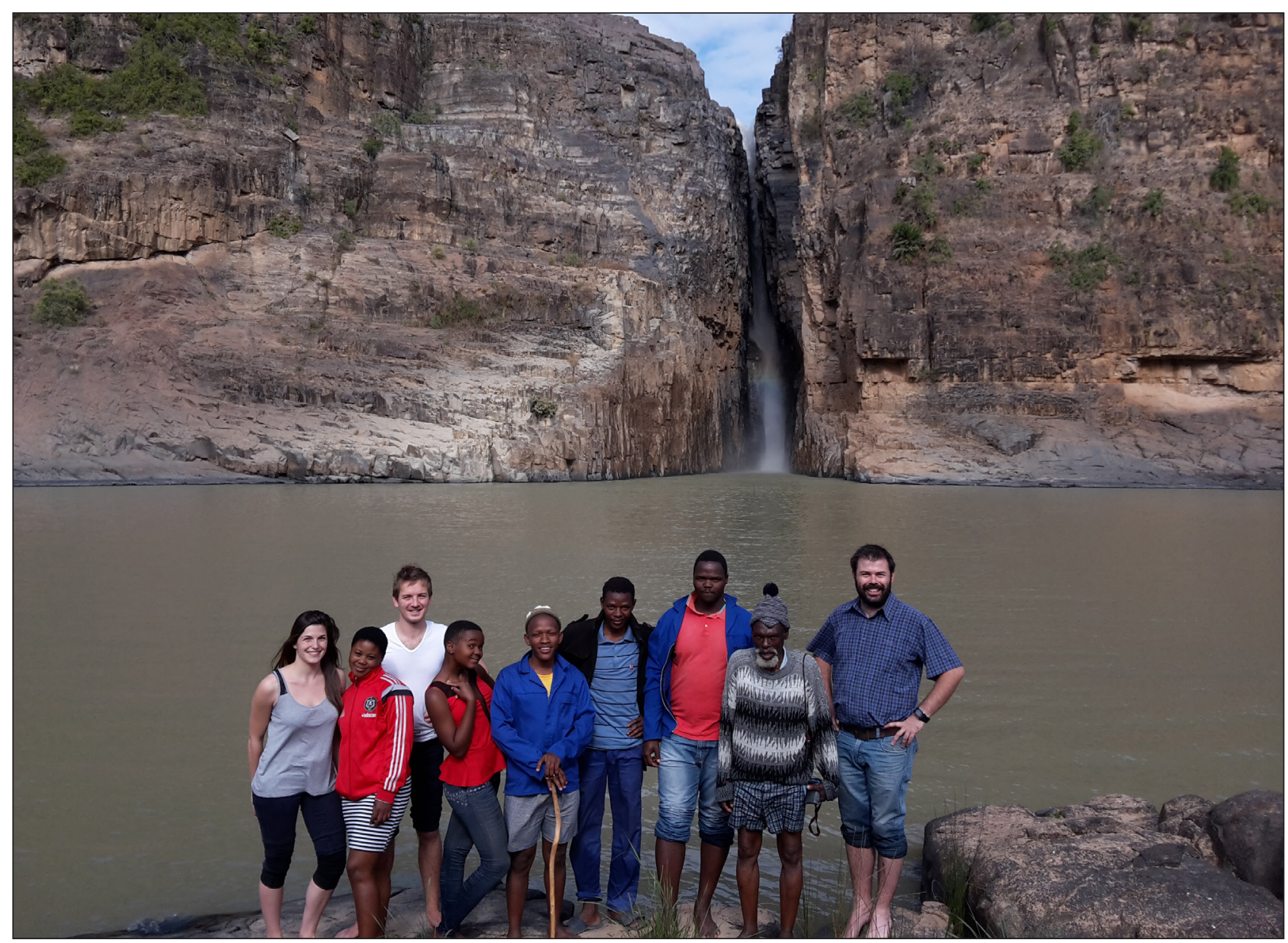

Figure 7

Kwa Madiba site visit: Thina Falls downstream

and maintenance of the plant. The cost/benefit ratio is therefore calculated as the ratio of the capital cost of the SSHP and the cost of providing electrical infrastructure (transmission and distribution lines) to connect the rural settlement or community to the existing local or national electricity grid.

The component of the NPV for the operation cost estimate is used to calculate monthly instalments or operation cost fees to be paid by energy or electricity end-users in the SSHP network. These monthly operation fees could be entered back into the financial analysis to calculate a new NPV and IRR.

Neither the NPV nor the financial payback period has taken into account sales of SSHP generated electricity or operational cost fees recovered from the end-users. Taking these figures into account increases the NPV and IRR and reduces the financial payback period

The following summarises the financial analyses for the proposed SSHP at Kwa Madiba. Table 2 shows the total capital cost for the development of a SSHP at the Kwa Madiba proposed site.

With the calculated capital cost and the methodology discussed for the financial analysis, the site was analysed and the following results obtained:

- Net present value (NPV)

$=\operatorname{R} 9481367.00$

- Internal rate of return (IRR)

$=9.68 \%$

- Levelised cost of energy

$=102.58 \mathrm{c} / \mathrm{kWh}$

- Financial payback period

$=22-23$ years

- Cost/benefit ratio

\section{ANALYSIS AND RESULTS}

The feasibility of the SSHP can be approached in several different ways depending on the type of development or funding model of the SSHP project.

Firstly, if the development of the SSHP is a commercial development and profit based, the feasibility of the project will be determined solely on the internal rate of return (IRR) on the investment.

Secondly, if the development of the SSHP is by a nonprofit organization or a government grant and revenue is only obtained to cover the initial capital cost and operation and maintenance costs, the feasibility of the project will be determined by a positive NPV.

Thirdly, if the development of the SSHP is for rural electrification for remote communities not connected to the local or national electricity grid, a cost/benefit ratio of less than 1 will determine the feasibility of the project. The cost/benefit ratio is calculated as the ratio of the capital cost of the SSHP to the cost of providing electrical infrastructure (transmission and distribution lines) to connect the rural settlement or community to the existing local or national electricity grid. The cost of connecting the rural communities to the local or national electricity grid in Sub-Saharan Africa is estimated as between R 1200 and R1 300 per metre by the World Bank (Deichmann et al., 2011). This estimation compares well with the results of similar research done by local consulting companies. 
For the purposes of the research the focus was on the latter two examples as well as the levelised cost of the SSHP as per the implementation model. Therefore the feasibility of the proposed Kwa Madiba SSHP installation was evaluated on NPV and cost/ benefit ratios and the levelised cost compared with the levelised cost of extending the existing national electrical grid to provide Kwa Madiba with electricity. From the costing it can be seen that the Kwa Madiba SSHP scheme is feasible both because of the positive NPV of the scheme as well as the cost/benefit ratio being below 1 .

The results of the Kwa Madiba SSHP plant financial analysis were used to evaluate a generic SSHP plant with similar technical characteristics as that of the Kwa Madiba SSHP plant. The head and flow of the Kwa Madiba SSHP scheme were kept constant and the penstock length and diameter and transmission line lengths were varied to obtain a chart for the design of feasible SSHP projects in terms of a positive NPV. Figure 8 shows the developed design chart for positive NPV. The diagonal lines for the different penstock diameters represent a zero NPV. The area underneath the diagonal lines represents a positive NPV and therefore a feasible installation; the area above the diagonal lines represents a negative NPV and therefore an unfeasible installation or project.

Similarly to the developed design chart for positive NPV for SSHP, a chart for a cost/benefit ratio of less than 1 for different penstock diameters was developed. Figure 9 shows an example of such a chart for a $355 \mathrm{~mm}$ diameter penstock $(Q=150 \mathrm{~L} / \mathrm{s}$; $\mathrm{H}=50 \mathrm{~m}$ ), with the diagonal lines representing a cost/benefit ratio of 1.00. Everything below the line is a cost/benefit ratio of less than 1.00 and therefore feasible and everything above the line is a cost/benefit ratio of more than 1.00 and therefore infeasible. The different diagonal lines were constructed using different lengths to the existing electricity grid as can be seen in the legend. A similar approach can be followed to develop charts for cost/ratio benefits of different configurations and SSHP projects.

The Kwa Madiba SSHP plant was also evaluated on the levelised cost of the project. The levelised cost of the SSHP is defined as the total cost of the SSHP project over the full operational lifespan of the system divided by the total energy generated over the lifespan of the system. Several different variations of the Kwa Madiba SSHP plant were obtained by varying the penstock diameter, penstock length and transmission line length. These variations were modelled as different scenarios and the levelised cost calculated and compared to that of fossil-fuel-generated grid-connected electricity. The levelised cost of electricity as generated by Eskom is between 70 and $80 \mathrm{c} / \mathrm{kWh}$ (EPRI, 2012). Table 3 shows the SSHP scenarios analysed based on levelised cost and compared to a levelised cost for Eskom to extend the existing grid and supply the remote rural community with electricity. This comprises of the $80 \mathrm{c} / \mathrm{kWh}$ levelised cost for Eskom generation as well as a levelised cost for the grid extension for different distances of the existing grid from the remote rural community. The comparison of the levelised costs is seen in Fig. 10.

From Fig. 10 it can be seen that the levelised cost extending the national or local electricity grid for rural electrification is less than the levelised cost for a SSHP project, where the grid extension is less than $1 \mathrm{~km}$. Due to the high cost of electrical transmission and distribution infrastructure, the levelised cost of existing grid extension increases exponentially with an increase in the length of the grid extension. At a required existing grid extension of more than $2 \mathrm{~km}$, all the evaluated scenarios in Fig. 9 have a lower levelised cost than that of the existing local or national grid extension.

\begin{tabular}{|c|c|c|c|}
\hline \multicolumn{4}{|c|}{$\begin{array}{c}\text { TABLE } 2 \\
\text { Capital cost }\end{array}$} \\
\hline Item & Description & Amount & $\%$ of capital cost \\
\hline A & PLANNING AND DESIGN COSTS & R 555194.30 & $11 \%$ \\
\hline A.1 & Pre-feasibility study & R 50000.00 & \\
\hline A. 2 & Design & R 374218.00 & \\
\hline A.3 & Legal and regulatory & R 74843.60 & \\
\hline A.4 & Environmental and social assessment & R 56132.70 & \\
\hline B & CIVIL WORKS & R 1337910.83 & $27 \%$ \\
\hline B.1 & Preliminary \& general cost & R 190971.79 & \\
\hline B.2 & Preparation of site & R 27356.69 & \\
\hline B.3 & Turbine room & R 180015.09 & \\
\hline B.4 & Inlet works & R 35895.13 & \\
\hline B.5 & Tailrace works & R 55962.73 & \\
\hline B.6 & Pipework and valves (supply and install) & R 847709.41 & \\
\hline C & ELECTRO-MECHANICAL EQUIPMENT & R 2343804.15 & $48 \%$ \\
\hline C.1 & Turbines & R 691200.00 & \\
\hline C. 2 & Generators & Incl. in Turbines & \\
\hline C.3 & Controls units & Incl. in Turbines & \\
\hline C. 4 & $\begin{array}{l}\text { Transformer cost and integration into electrical grid (Transmission } \\
\text { infrastructure) }\end{array}$ & R 1514364.15 & \\
\hline C.5 & Import costs & R 138240.00 & \\
\hline D & IMPLEMENTATION COST & R 684161.72 & $14 \%$ \\
\hline D.1 & $\begin{array}{l}\text { Commissioning, erecting and project management provided by the } \\
\text { Supplier }\end{array}$ & R 117190.21 & \\
\hline D.2 & Construction supervision (Consultant) & R 276128.62 & \\
\hline D.3 & Training & $\mathrm{R} 20736.00$ & \\
\hline D.4 & Spare components to be stored on site & R 20736.00 & \\
\hline D.5 & Integration of system components & R 41472.00 & \\
\hline D.6 & Contingencies & R 207898.89 & \\
\hline TOTAL: & & R4 921071.01 & $100 \%$ \\
\hline
\end{tabular}




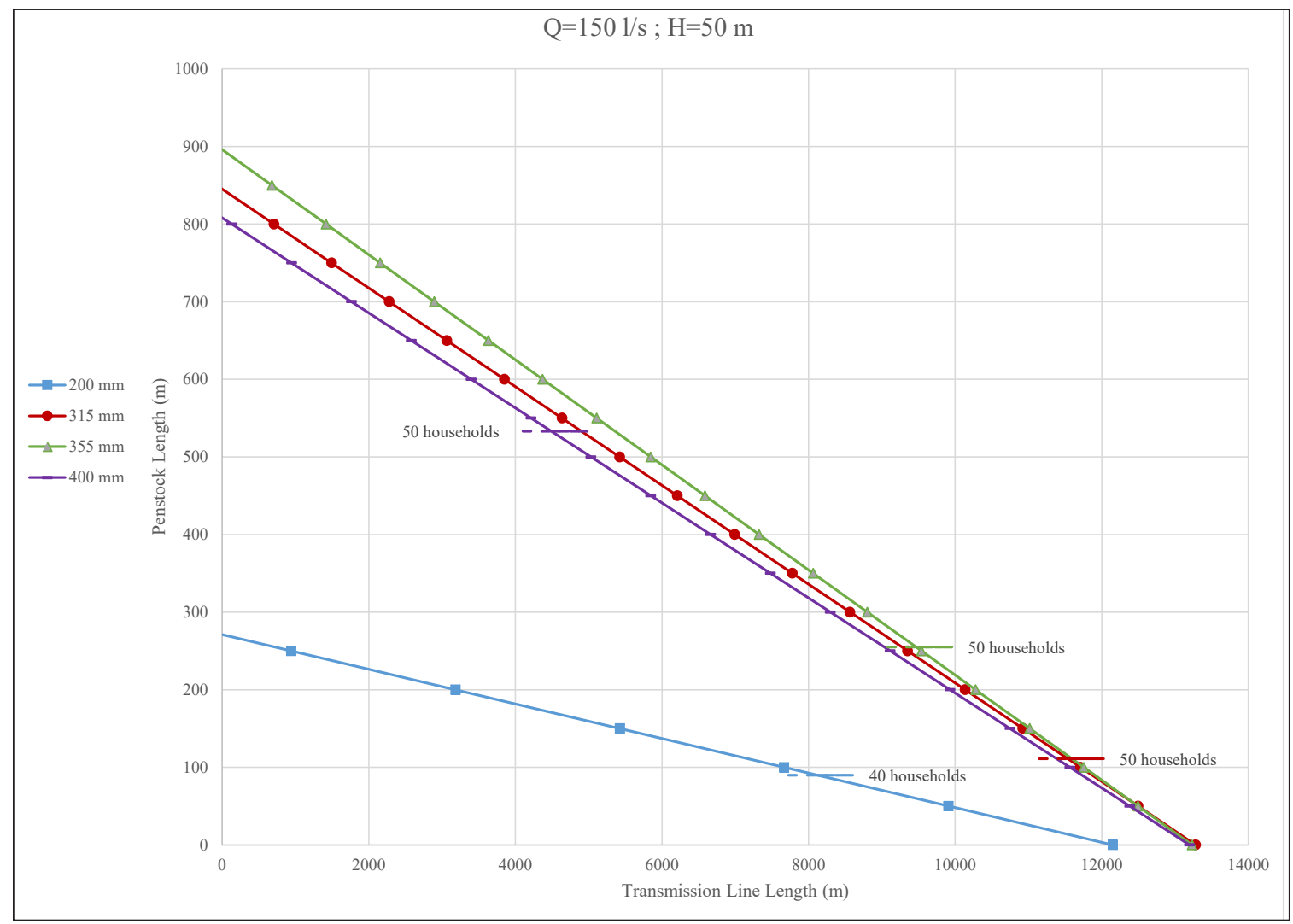

Figure 8

Feasibility analysis: Design chart - NPV

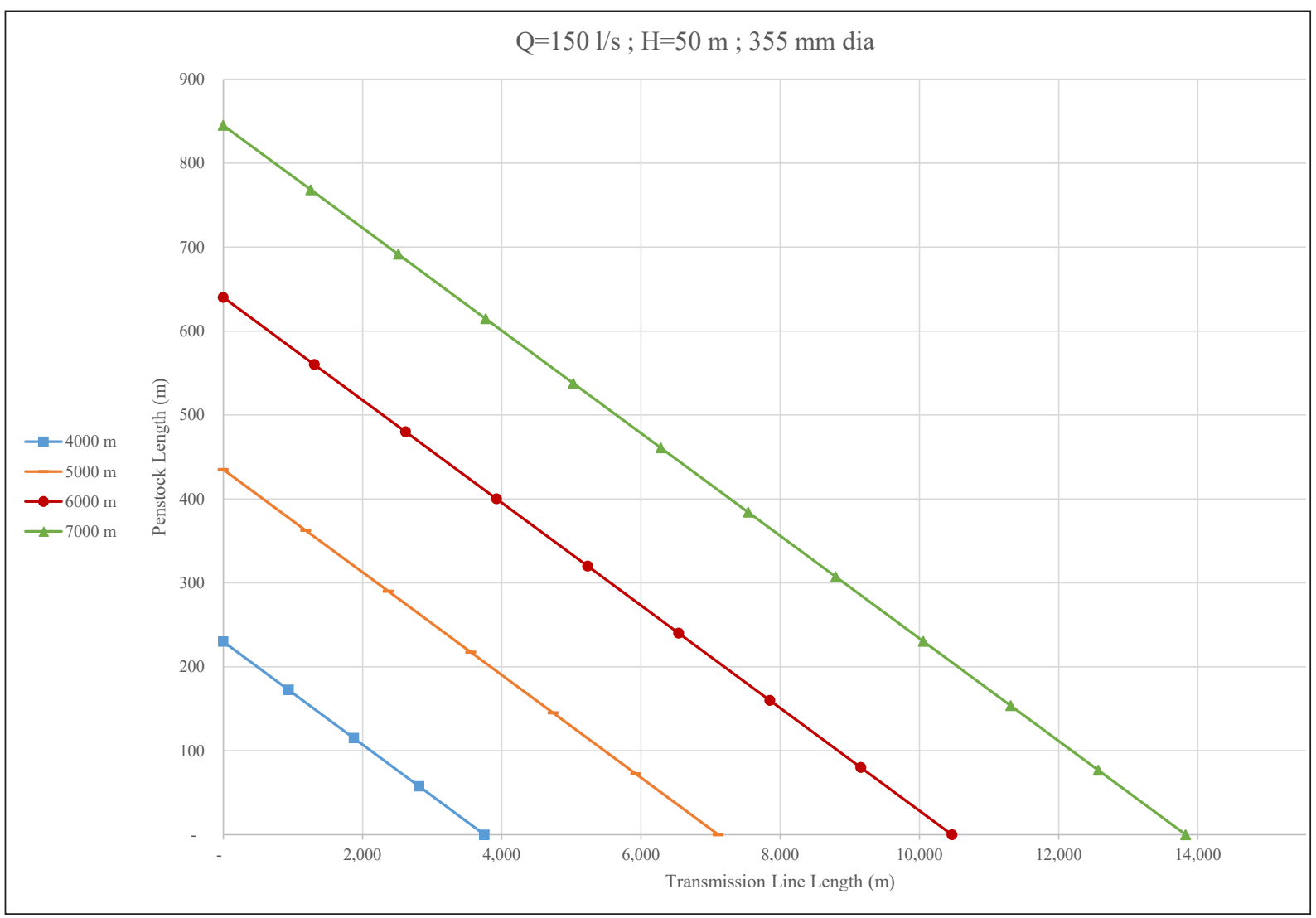

Figure 9

Cost/benefit ratio chart 


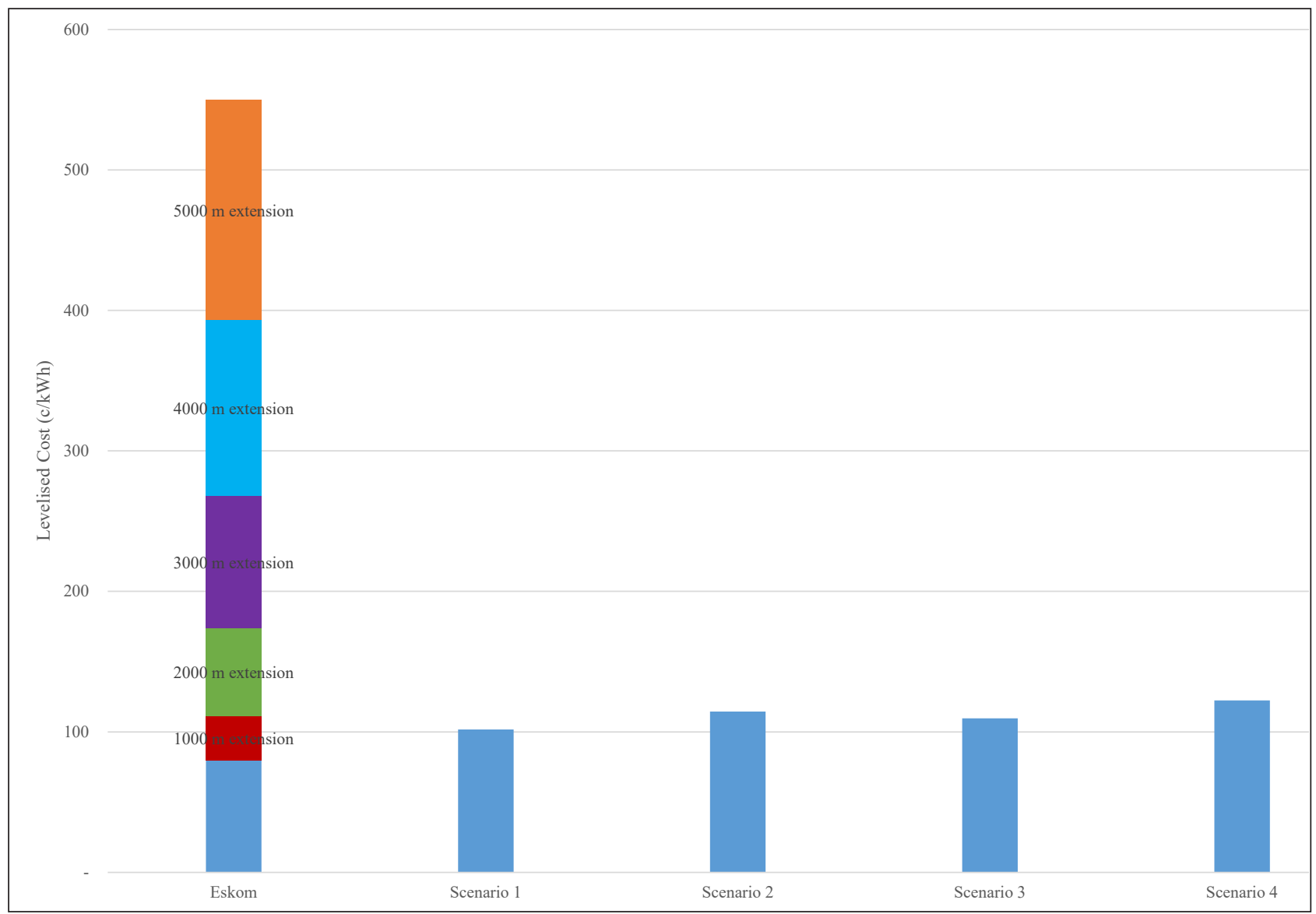

Figure 10

Levelised cost comparison

The escalation of energy costs is a major factor in the NPV of a SSHP project. The calculations on the Kwa Madiba SSHP plant were done on an estimation of escalation of energy costs of $10 \%$. Figure 11 shows a comparison of the NPV for different escalation of energy costs of the Kwa Madiba SSHP scheme. The other parameters of the scheme are kept constant.

An alternative to both the grid extension and the SSHP project is the use of diesel generators as electricity supply. As the following example shows, the initial capital cost of a diesel generator is low compared to the initial capital cost of a SSHP project, although the operating cost and cost of diesel over the operating lifetime of the generator becomes excessively high compared to the operating cost of the SSHP.

A diesel generator alternative to the $50 \mathrm{~kW}$ SSHP plant at Kwa Madiba is as follows:

- $64 \mathrm{kVA}(50 \mathrm{~kW})$

- $\quad$ Cost $=$ R 390,997 (Generator + Distribution) (Market related quotation form industry - 28 October 2015)

- Fuel consumption=17 L/h @ full load

- $\quad$ Diesel price $($ on $28 / 10 / 2015)=\mathrm{R} 10.93$

- $\quad$ Diesel cost (Year 1) = R 542565 (8 h/day)

Figure 12 shows a comparison of the cost of SSHP, grid extension and the diesel generator alternative for the Kwa Madiba SSHP project.

\begin{tabular}{|c|c|c|c|c|}
\hline \multicolumn{5}{|c|}{ TABLE 3 } \\
\hline SSHP scenarios for levelised cost comparison \\
\hline 1 & $50 \mathrm{~kW}$ & $355 \mathrm{~mm}$ & $100 \mathrm{~m}$ & $1000 \mathrm{~m}$ \\
\hline 2 & $50 \mathrm{~kW}$ & $355 \mathrm{~mm}$ & $100 \mathrm{~m}$ & $2000 \mathrm{~m}$ \\
\hline 3 & $50 \mathrm{~kW}$ & $355 \mathrm{~mm}$ & $200 \mathrm{~m}$ & $1000 \mathrm{~m}$ \\
\hline 4 & $50 \mathrm{~kW}$ & $355 \mathrm{~mm}$ & $200 \mathrm{~m}$ & $2000 \mathrm{~m}$ \\
\hline Eskom & $\begin{array}{l}\text { Variable } \\
\text { grid exten- } \\
\text { sion lengths }\end{array}$ & & $\begin{array}{c}\text { Penstock } \\
\text { length } \\
\text { sion line } \\
\text { length }\end{array}$ \\
\hline
\end{tabular}

\section{CONCLUSIONS}

As a result of the methodology followed in conducting the case study of the Kwa Madiba SSHP scheme according to the developed implementation model, the following main conclusions can be drawn:

- Small-scale hydropower is a feasible alternative for rural electrification and at specific distances away from the local and national electricity grid it is a better alternative than grid extension. Furthermore small-scale hydropower is a technically possible solution within the South African context and legal framework.

- The levelised cost of SSHP projects indicate that the cost of SSHP for low energy generation is high compared to the 


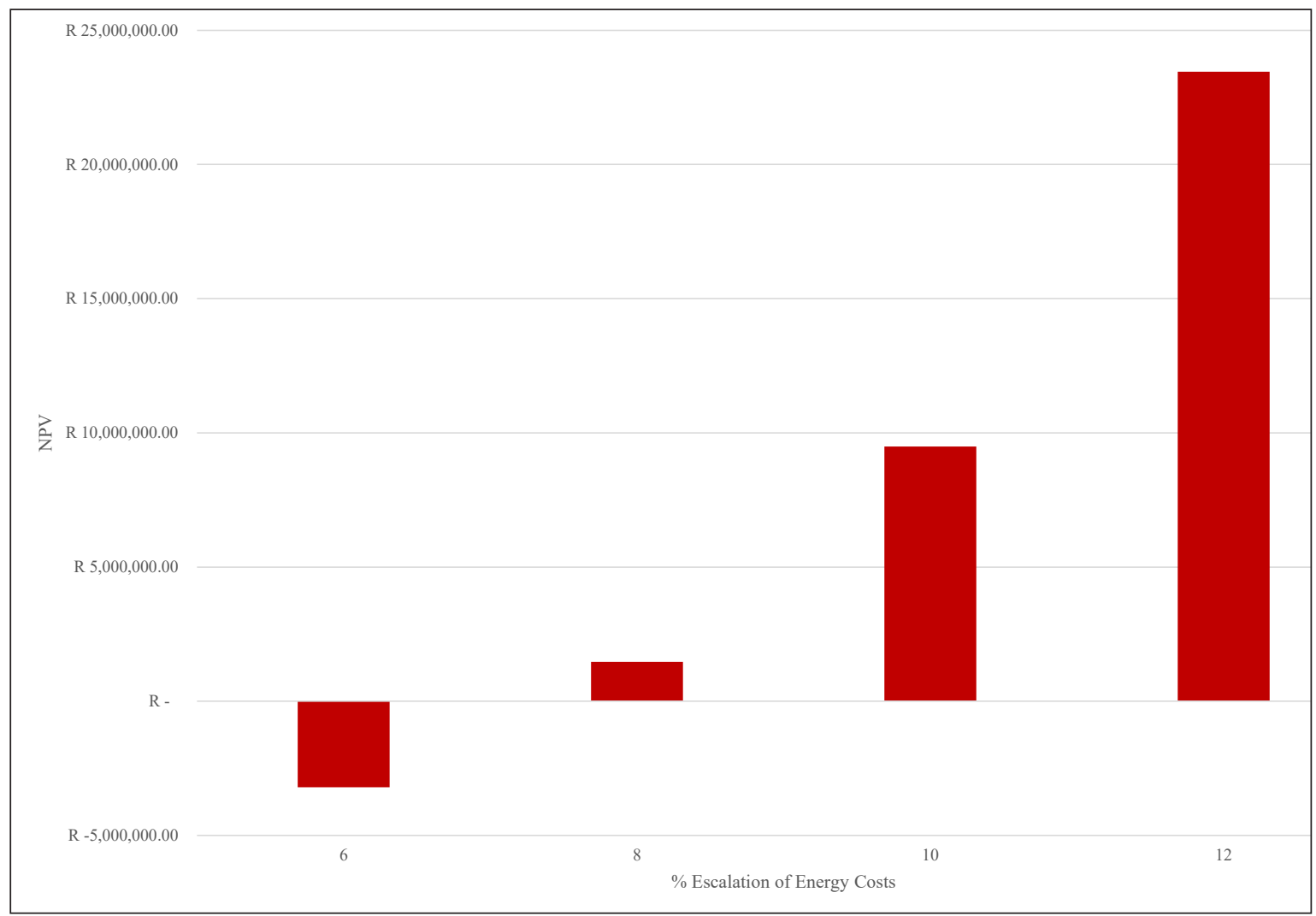

Figure 11

Escalation of energy costs - NPV comparison

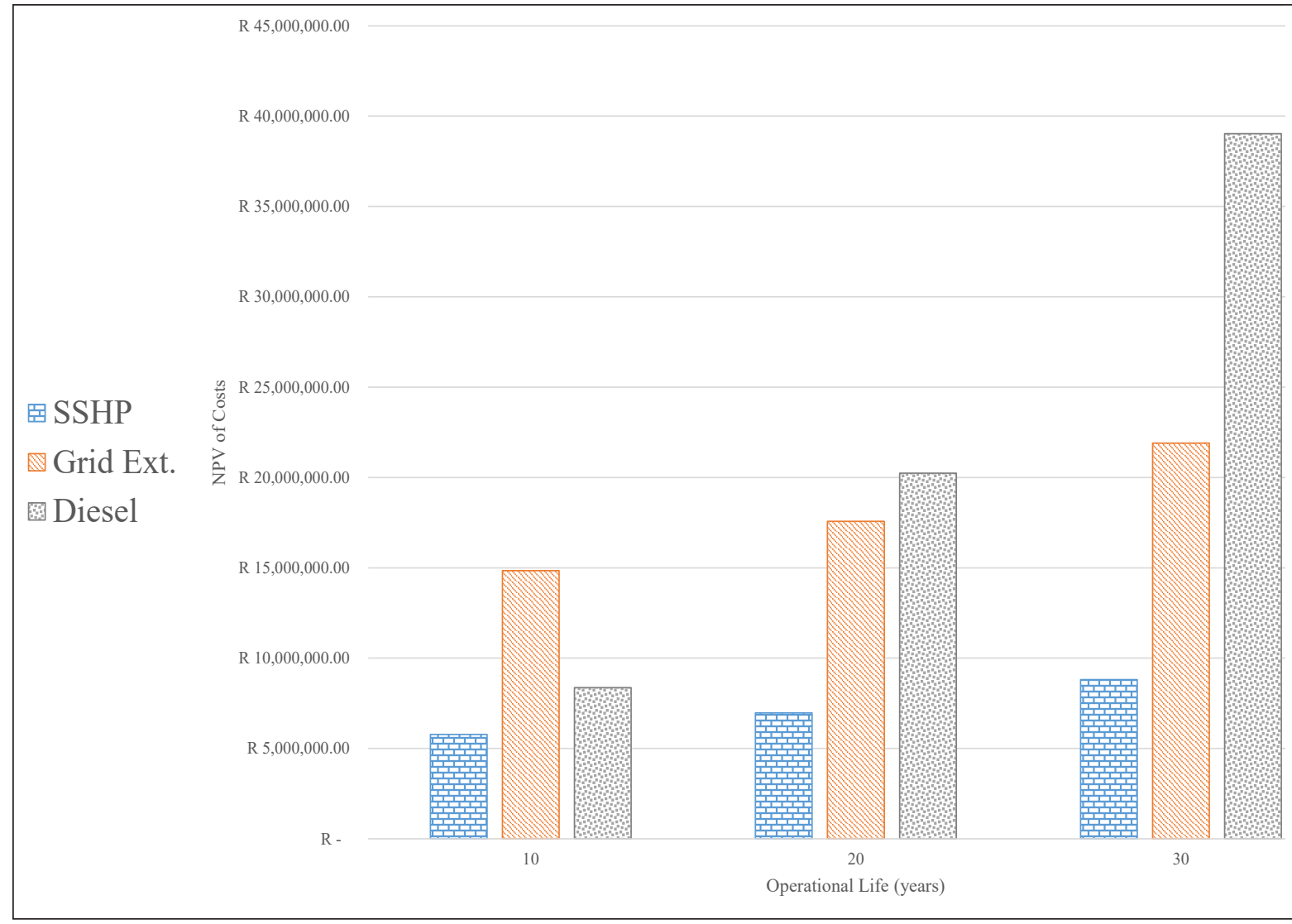

Figure 12

Kwa Madiba alternative energy sources: cost comparison 
levelised cost of grid connected electricity supply; however, the remoteness of SSHP for rural electrification and the cost of infrastructure to connect remote rural communities to the local or national electricity grid provides a low cost/benefit ratio and renders SSHP for rural electrification feasible on this basis.

Several additional conclusions supplementary to the main conclusion were made. These should be read and understood within the context of the research and are used to further motivate and authenticate the conclusions above. The following conclusion were made supplementary to the main two conclusions:

- Head becomes a governing factor for potential sites, as higher flows necessitate larger turbines and increase development costs.

- The additional electricity generation capacity outweighs the costs of increased diameter penstocks due to the high escalation rate of electricity costs in South Africa.

- For shorter lengths of transmission lines the SSHP is feasible based on NPV.

- Long lengths of transmission line makes SSHP unfeasible based on NPV.

- Some technically possible SSHP projects have negative NPV based on long transmission line lengths or low income from power generated, but are still possible for rural electrification.

- The cost/benefit ratio is a more accurate calculation for feasibility of SSHP for rural electrification.

- Turbine cost and distribution line cost are the major influences on the cost and feasibility of SSHP.

- High head, short transmission line and islanded mini-grid SSHP installations are the most feasible.

- Levelised cost of SSHP is high for low power generation.

- Cost/benefit ratios for SSHP with high levelised cost still indicate feasibility of SSHP for rural electrification.

\section{ACKNOWLEDGEMENTS}

This research was completed in conjunction with the Water Research Commission and the OR Tambo District Municipality within the Eastern Cape Province of South Africa. The opinions expressed are those of the author and do not necessarily represent the policy of the Water Research Commission. The authors acknowledge the provision of funds made available through the Department of Science and Technology and the Water Research Commission for the purpose of funding capacity building for the implementation of small-scale hydropower development for rural electrification in South Africa.

\section{REFERENCES}

BARTA B (2002) Baseline study - hydropower in South Africa. Department of Minerals and Energy. Capacity Building in Energy Efficiency and Renewable Energy. DME Report No. COWI P54126/EE/RE/70. Department of Minerals and Energy, Pretoria, South Africa.

CARRASCO F (2011) Introduction to Hydropower. World Technologies, Delhi.
CENSUS (2011) AFRIGIS CENSUS 2011 Portal. URL: http://www. census2011.co.za (Accessed 14 May 2015).

COLORADO ENERGY OFFICE (2007) Small Hydropower Handbook (e-book). The Colorado Energy Office. URL: http://www.colorado. gov/cs/Satellite?c=Document_C\&childpagename=GovEnergyOffice \%2FDocument_C\%2FCBONAddLinkView\&cid=1251643418897\&p agename $=$ CBONWrapper $($ Accessed 14 May 2015).

DEICHMAN U, MEISNER C, MURRAY S and WHEELER D (2011) The economics of renewable energy expansion in rural Sub-Saharan Africa. Energ. Polic. 39 (1) 215-227. http://dx.doi.org/10.1016/j. enpol.2010.09.034

EPRI (Electric Power Research Institute) (2012) Power generation technology data for integrated resource plan of South Africa. EPRI, Palo Alto, CA.

HALL DG (2006) Feasibility assessment of water energy resources of the United States for new low power and small hydro classes of hydroelectric plants (No. DOE/ID-11263). United States of America Department of Energy (DOE), Idaho National Laboratory.

LOOTS I, VAN DIJK M, BARTA B, VAN VUUREN SJ and BHAGWAN JN (2015). A review of low head hydropower technologies and applications in a South African context. Renew. Sust. Energ. Rev. 50 1254-1268. http://dx.doi.org/10.1016/j.rser.2015.05.064

MULLER J (1999) South African renewable energy resource database: Chapter 2 Modelling hydropower potential. CSIR, Pretoria.

OKOT DK (2013) Review of small hydropower technology. Renew. Sust. Energ. Rev. 26 515-520. http://dx.doi.org/10.1016/j.rser.2013.05.006

PUNYS P, DUMBRAUSKAS A, KVARACIEJUS A and VYCIENE G

(2011) Tools for small hydropower plant resource planning and development: A review of technology and applications. Energies 4 (9) 1258-1277. http://dx.doi.org/10.3390/en4091258

SZEWCZUK S, FELLOWS A and VAN DER LINDEN N (2000) Renewable energy for rural electrification in South Africa. FP5 JouleThermie Programme. European Commission, Brussels.

SZEWCZUK S (2015) Smart sustainable energy for the rural built environment. In: Proceedings of Congress on Smart and Sustainable Built Environments (SASBE), 9-11 December 2015, Pretoria.

VAN DIJK M, VAN VUUREN SJ, BHAGWAN J and LOOTS I (2014) Small-scale hydropower development for rural electrification in South Africa: Water engineering. Civ. Eng. 22 (5) 42-46.

WADE S, WADE D and MILTON G (2015) Wyoming Small Hydropower Handbook. Wenck Associates, Inc., Cheyenne, WY.

WAGNER HJ and MATHUR J (2011) Introduction to Hydro Energy Systems: Basics, Technology and Operation. Springer Science \& Business Media, Berlin.

ZHANG QF, SMITH BT and ZHANG W (2012) Small Hydro Reference Model Project (No. ORNL/TM-2012/501). Oak Ridge National Laboratory (ORNL). doi:10.2172/1055120. http://dx.doi. org/10.2172/1055120 